\title{
Oral Kaposi's sarcoma in Tanzania: Presentation, immunopathology and human herpesvirus-8 association
}

\author{
AMOS R. MWAKIGONJA ${ }^{1,2 *}$, FATEMEH PAK ${ }^{1 *}$, PAWAN PYAKUREL $^{1}$, INNOCENT J. MOSHA $^{2}$, \\ WILLY K. URASSA ${ }^{3}$, EPHATA E. KAAYA ${ }^{1,2}$ and PETER BIBERFELD ${ }^{1}$ \\ ${ }^{1}$ Immunopathology Laboratory, Department of Oncology-Pathology, Cancer Centrum Karolinska, Karolinska Institutet, \\ Stockholm, Sweden; Departments of ${ }^{2}$ Pathology, and ${ }^{3}$ Microbiology/Medical Immunology, Muhimbili University \\ College of Health Sciences, University of Dar es Salaam, P.O. Box 65001, Dar es Salaam, Tanzania
}

Received November 4, 2006; Accepted December 14, 2006

\begin{abstract}
Oral Kaposi's sarcoma (OKS) from Tanzanian patients (78) at Muhimbili National Hospital/Muhimbili University College of Health Sciences corresponding to approximately $10 \%$ of KS registered during 1990-2005, were diagnosed (ELISA) as HIV-infected (OAKS) (74/78) and endemic KS (4/78). Females were $69.2 \%$ (54/78) with median age 31 and males $30.8 \%$ (24/78) with median age 38 . More males (50\%) had systemic KS than females (37\%) and 4-times more multicentric OKS. All tested (34) oral KS patients sera had HHV-8 antibodies. Available (31/78) blood showed very low $\mathrm{CD} 4{ }^{+} \mathrm{T}-$-lymphocyte counts. Most OKS $(61.5 \%)$ had nodular histology. Immunostaining showed adult male nodular OAKS to have a significantly higher frequency of viral LANA ${ }^{+}$, endothelial CD34+ tumour spindle-cells (SC) and more $\mathrm{Ki}-67^{+}($median $=24.1 \%)$ proliferating cells compared to females $(17.2 \%)$. Juvenile nodular OAKS had more LANA ${ }^{+}$ and Ki-67+ cells than corresponding adult cases. Significantly more $\mathrm{LANA}^{+}$and $\mathrm{Ki}-67^{+}$cells were found in nodular OAKS compared to cutaneous HIV/AIDS Kaposi's sarcoma (CAKS). A positive correlation (60\%) was found between the proliferation index $\left(\mathrm{Ki}-67^{+}\right.$cell frequency) and $\mathrm{LANA}^{+} / \mathrm{CD} 34^{+}$ SC. OKS in Tanzania is since 1990, mostly seen in females, associated with HIV/AIDS and advanced (nodular) histopathology. Males have more systemic tumour burden while more females develop primary OAKS. HHV $-8^{+}$cells were more frequent in nodular male than female and in juvenile
\end{abstract}

Correspondence to: Dr Amos Rodger Mwakigonja, Immunopathology Laboratory, Department of Oncology-Pathology, Cancer Centrum Karolinska, R8:00, Karolinska Hospital/Institute, S-171 76 Stockholm, Sweden

E-mail: amos.r.mwakigonja@ki.se

\section{${ }^{*}$ Contributed equally}

Key words: oral, Kaposi's sarcoma, human herpesvirus-8, AIDS, immunohistochemistry, Tanzania than adult nodular OAKS than cAKS. Higher tumoral HHV-8 content appeared to be correlated to proliferation index.

\section{Introduction}

Kaposi's sarcoma (KS) was rare when first described by Moritz Kaposi (1872) in Europe (1). It is now recognized to be pathognomonically associated with the novel human herpesvirus type 8 (HHV-8) also known as Kaposi's sarcomaassociated herpesvirus (KSHV) (2), and has become the most important HIV/AIDS-associated malignancy in various subSaharan countries including Tanzania in terms of frequency, morbidity and mortality (2-4). The frequency of HIV/AIDS KS (AKS) in comparison with endemic KS (EKS) continues to increase with the HIV epidemic and oral KS (OKS) is recognized as a frequent manifestation of AIDS $(5,6)$ but little studied in Africa including Tanzania. The presence of HHV-8 latency-associated nuclear antigen (LANA) is known to discriminate KS from non-KS tumours by immunohistochemistry (IHC) with high sensitivity and specificity and is therefore comparable to real-time polymerase chain reaction (PCR) for evaluation of KS tissues $(7,8)$. However, tissue-based IHC/immunofluorescence (IFA) studies on oral KS are apparently, lacking and reports on KS proliferative activity are few, limiting evaluation of their pathogenesis and possible formulation of preventive and therapeutic protocols $(4,6,7,9,10)$. Most documented KS immunohistochemistry (IHC) studies were performed on cutaneous biopsies, while reports on oral cases mainly concerned molecular studies of buccal swabs and saliva $(4,6,7,9,10)$. Tissue differences in tumour cell proliferation and HHV-8 cell association (content) in terms of viral load (PCR) and LANA expression with increasing KS tumour stage have been reported previously $(4,11)$ but no comparison between sexes and age-groups and between OKS and cutaneous KS are documented. Demographically, KS was previously related mostly to males (homosexuals, bisexuals and IV drug addicts) in developed and developing countries which suggested a possible biological gender or sexual behaviour relatedness $(4,12-14)$. However, the continuous narrowing of male to female ratio and high AKS frequency in female sex workers and sexually transmitted disease (STD) patients in sub-Saharan Africa seem to 
indicate the importance of a sexual route of KSHV/HHV-8 transmission $(15,16)$. HHV-8/KSHV has been found in oral (saliva) $(5,9,17)$ and genital (semen and cervical/vaginal) fluids $(5,12,18)$ suggesting an important role for genital-oral and oral-oral HHV-8 transmission in KS development (17-19). Anatomical studies of OKS reported the palate, gingiva and tongue as commonly affected sites $(6,20)$. OKS appears prognostically less favourable than cutaneous forms (20) suggesting differences in susceptibility of mucosal and other tissues although few African data are available (14,17). The present study further elucidates viral and cell biological aspects of oral KS in order to allow formulation of preventive and therapeutic strategies.

\section{Materials and methods}

Biopsies. Archival formalin-fixed, paraffin-embedded (FFPE) diagnostic biopsies and corresponding medical records of 78 Tanzanians with oral KS, processed at the Department of Histopathology, Muhimbili National Hospital (MNH)/Muhimbili University College of Health Sciences (MUCHS) in Dar es Salaam between 1990 and 2005 were retrieved and further evaluated at the Immunopathology Lab, Karolinska Institute, Stockholm. Of these, 29 oral KS (OKS) biopsies were selected with regard to tumour content of 40$90 \%$, minimal necrosis/haemorrhage, and diagnostically clear nodular or plaque histology but not patch KS for immunofluorescence (IFA) studies of HHV-8 LANA cell association and tumour proliferation as Ki-67 expression. These cases were compared with 21 cutaneous KS biopsies matched to the OKS cases for age, sex, HIV and HHV-8 serostatus, histological grade, tissue block size (quantity of biopsy), section size, tumour content and degree of haemorrhage and necrosis. Furthermore, an unmatched comparison across genders, age-groups and anatomical (oro-cutaneous) presentation was performed. None of the patients included in this study had received any antiretroviral (ARV) or tumour therapy before the biopsy was taken.

Histological evaluation. Biopsy sections (5 $\mu \mathrm{m})$ were deparaffinized (in xylene), stained with haematoxylin and eosin (H\&E) (21) and reviewed independently by three Pathologists (ARM, EEK and PB) who also selected biopsies for IFA.

Immunohistochemistry. Briefly, deparaffinized sections $(5 \mu \mathrm{m})$ were taken through descending grades of alcohol, and heated in a microwave at $750 \mathrm{~W}$ for $6 \mathrm{~min}$ after boiling point in $0.1 \mathrm{M}$ citrate buffer ( $\mathrm{pH}$ 6.0) for antigen retrieval. After cooling (30 $\mathrm{min}$ ) at room temperature (RT), quenching of endogenous peroxidase was performed by treatment with $30 \%$ hydrogen peroxidase in distilled water ( $30 \mathrm{~min}$ at RT) before avidinbiotin immunoperoxidase (ABC) staining, as previously described $(11,21)$. Sections were also immunostained with triple-marker IFA for LANA, CD34 [endothelial/KS spindlecell (SC)] and Ki-67 markers (Table I) as previously described (11). Number of positive cell nuclei per section was evaluated after staining for DNA with 6-diamidino-2-phenylindole (DAPI) solution (10 $\mu \mathrm{M}$ DAPI in $800 \mathrm{mM}$ disodiumhydrogenphosphate) (Sigma D9542, Sigma-Aldrich, St. Louis,
MO, USA) (4). Negative controls included Tris-buffered saline (TBS) instead of primary antibody and antigen negative tissue sections including normal and peri-lesional biopsy areas. Positive controls included FFPE sections of HHV-8 LANA ${ }^{+}$cells from a body cavity-based lymphoma (BCBL-1) and sections of a selected reference case of cutaneous nodular AKS. The number of $\mathrm{LANA}^{+}$cells/HPF (x400 magnification) and $\mathrm{LANA}^{+}$granules/nucleus $\left(\mathrm{L}^{+} \mathrm{gr} / \mathrm{n}\right)$, $\mathrm{CD}^{4} 4^{+}, \mathrm{LANA}^{+} / \mathrm{CD} 34^{+}$(double positive), $\mathrm{Ki}-67^{+}$and $\mathrm{LANA}^{+} / \mathrm{CD}^{2} 4^{+} / \mathrm{Ki}-67^{+}$(triple positive) cells was evaluated on micrographs.

Microscopy. Photomicroscopy (Olympus BX60, Tokyo, Japan) with a digital camera (Sony DKC-5000, Tokyo, Japan) and different filters for fluorescence microscopy was used to document bright fields as well as specific FITC, Cy3, Cy5, and DAPI fluorescence images which were edited and overlaid using Adobe Photoshop 7.0 (Adobe Systems Incorporated, San Jose, CA, USA). Representative cells were evaluated by visual scoring of colour micrographs in eight adjacent high power fields (HPF) of characteristic lesions and cells positive for individual markers and combinations calculated as a percentage of DAPI-stained nuclei. The percentage proliferating $\left(\mathrm{Ki}-67^{+}\right)$cells per total number of DAPI-staining cell nuclei in a HPF was designated as proliferation index.

\section{Serology}

HIV serology. HIV-1 evaluation was performed (Department of Microbiology/Immunology MUCHS) on KS sera by doubleELISA assays (serial) as previously described $(22,23)$.

$H H V-8$ serology. HHV-8 serology was carried out on available oral KS patient sera at the Swedish Institute for Infectious Diseases Control, Stockholm, by IFA for antibodies to HHV8 antigens using two B-cell lines (BCP-1 and BCBL-1) infected with HHV-8 as previously described (12).

Immunology. CD4, CD8 lymphocytes, and total white blood cell counts (WBCC) of OKS patients were evaluated (Department of Microbiology/Immunology MUCHS) using Immuno-flow cytometry (MicroDif 18 Coulter CounterCoulter Electronics, Luton, London, UK) as previously described (24). The cut-off point for normal WBCC in Tanzania was at $4.5 \times 109$ as previously described (24) but the study designated cut-off point for immuno-deficiency was a CD4/CD8 ratio $<0.5$ (or CD4 counts $<200 \mathrm{~T}$-cells $/ \mu \mathrm{l}$ ) and 0.1 (CD4 counts $<50 \mathrm{~T}$-cells $/ \mu 1$ ) for severe immunodeficiency.

Statistical analysis The EPI INFO 6 statistical software programme (CDC, Atlanta, GA) and Microsoft Excel (Microsoft Corporation, Redmond, WA, USA) were used. The $p$-values of $\leq 0.05$ were considered statistically significant. Comparison of normally distributed sample means was performed using analysis of variance (ANOVA) while nonparametric (Kruskal-Wallis) tests and the Fisher exact test were used to analyze smaller sample sizes. Furthermore, medians rather than means were used to express and compare central tendency in small samples. 
Table I. Antibodies $(\mathrm{Ab})$ used in stainings by immunofluorescence and/or peroxidase.

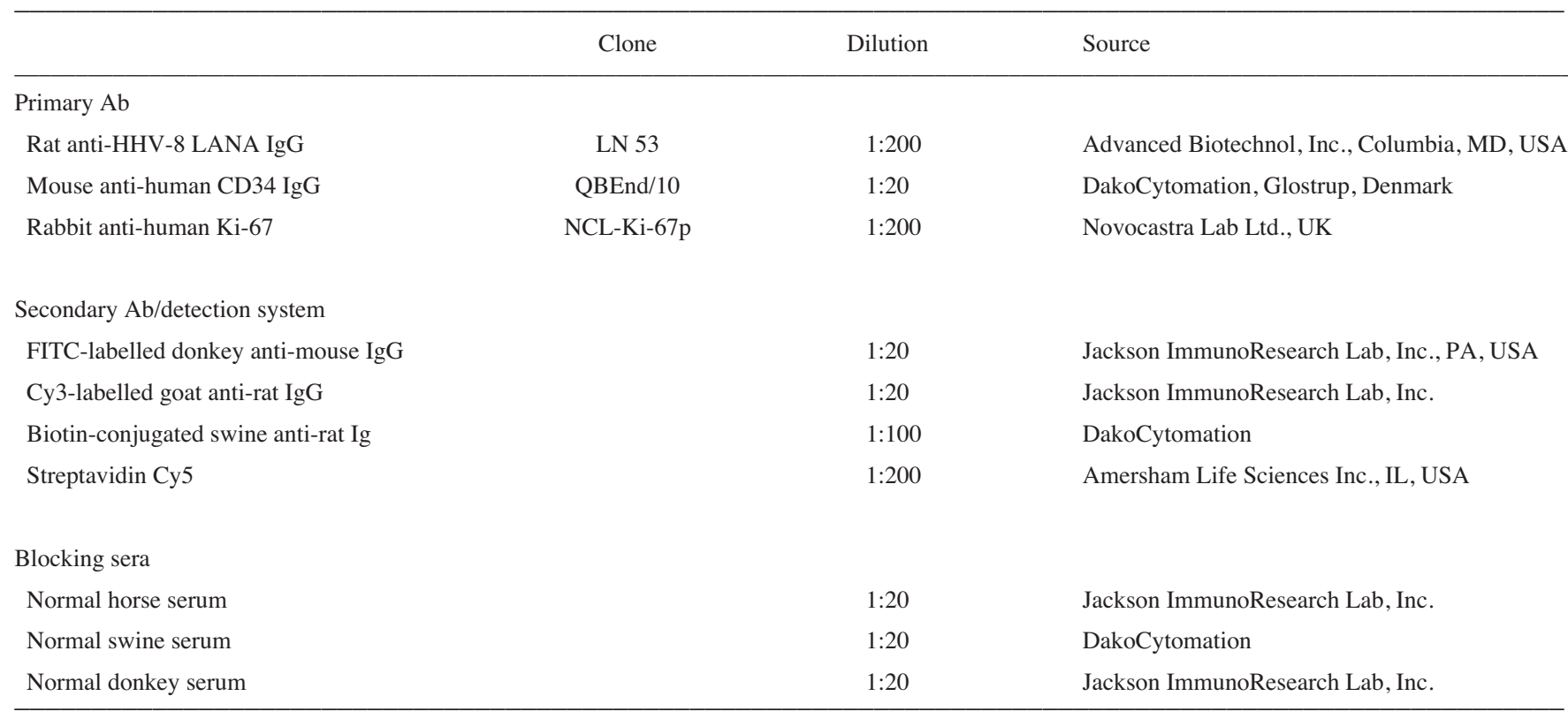

Table II. Demographic, clinical and histological distribution of oral KS at Muhimbili National Hospital from 1990-2006.

\begin{tabular}{|c|c|c|c|c|c|c|c|c|c|c|c|c|}
\hline Gender & $\begin{array}{l}\text { Median } \\
\text { age } \\
\text { (years) }\end{array}$ & $\begin{array}{l}\text { Age range } \\
\text { (years) }\end{array}$ & \multicolumn{2}{|c|}{ Extent of disease (\%) } & \multicolumn{3}{|c|}{ Histological stage (\%) } & Total & \multicolumn{3}{|c|}{$\begin{array}{l}\text { Histological stage and extent } \\
\text { of all oral } \mathrm{KS}(\%)\end{array}$} & Total \\
\hline Male & 38 & $6-55$ & $12(50.0)$ & $12(50.0)$ & $8(33.0)$ & $5(21.0)$ & $11(46.0)$ & $24(30.8)$ & Early KS & $10(33.3)$ & $20(66.7)$ & $30(38.5 \%)$ \\
\hline Both & 32 & $4-55$ & $46(59.0)$ & $32(41.0)$ & $17(21.8)^{\mathrm{a}}$ & 13 (16.7) & $48(61.5)$ & $78(100.0)$ & Total & $46(59.0)$ & $32(41.0)$ & $78(100.0)$ \\
\hline
\end{tabular}

Early KS $=$ patch + plaque stage. ${ }^{\mathrm{a} N o t}$ included in the immunohistology study. ${ }^{\mathrm{b}}$

\section{Results}

Demography. A total of 78 oral KS cases, 24 males (30.8\%) and 54 females $(69.2 \%)$ were collected (male to female ratio $\approx 1: 2)$ out of approximately $700 \mathrm{KS}(11.1 \%)$ biopsies from 465 males and 235 females (male to female ratio $\approx 1: 2$ ) of which 488 were AKS (69.7\%), 100 were EKS (16.0\%) and 112 were of unknown HIV status registered between 1990 and 2005. The median age for OKS males and females (p-value $=0.03$ ) was 38 and 31 years respectively (Table II). Five OKS patients $(6.7 \%)$ were children $(<15$ years $)$ and 3 $(4.0 \%)$ were middle-aged $(\geq 50)$, thus most cases $(93.3 \%$, $70 / 75)$ represented the sexually most active age-group (15-49), with a peak frequency at age $25-35$ years $(58.7 \%, n=44 / 75)$.

Clinical presentation. Most patients (46/78, 59.0\%) presented with primary, clinically localized OKS but a greater proportion $(50.0 \%)$ of males than females $(37.0 \%)$ presented with disseminated KS at first diagnosis (Table II). The clinical records seem to indicate that males were 4-times more likely to have multicentric OKS than females. Palatal KS lesions
(Fig. 1a) were most frequent $(55.1 \%, 43 / 78)$ followed by the tongue (Fig. 1b) $(25.6 \%, 20 / 78)$ whereas buccal mucosa $(23.1 \%, 18 / 78)$, and other sites (tonsils, oropharynx) were rare. All patients $(n=6)$ with concurrent opportunistic infections [pulmonary tuberculosis (4/6) and oral thrush $(2 / 6)]$ were females. Haemorrhage was a presenting symptom in $6.4 \%(5 / 78)$ patients while $3.8 \%(3 / 78)$ had fungating lesions.

Serology and immunology. ELISA studies on all (78) OKS sera showed that $74(94.9 \%)$ were seropositive for HIV (AKS) and $4(5.1 \%)$ cases were negative (EKS). Available (34) OKS sera (33 AKS, 1 EKS) which could be screened by IFA microscopy for anti-HHV-8 antibodies were positive. All (21) cutaneous KS selected for matched immunohistology studies were HIV and HHV-8 seropositive. Cell counts (FACS) of available (31) OAKS patient blood showed that $25(80.7 \%)$ had CD4 values $<10 \mathrm{~T}$-cells $/ \mu 1$ and none $>50 \mathrm{~T}$-cells $/ \mu 1$. Concordantly, most patients $(24 / 31)$ (77.4\%) had a CD4/CD8 ratio $<0.1$ implying severe immunodeficiency. 


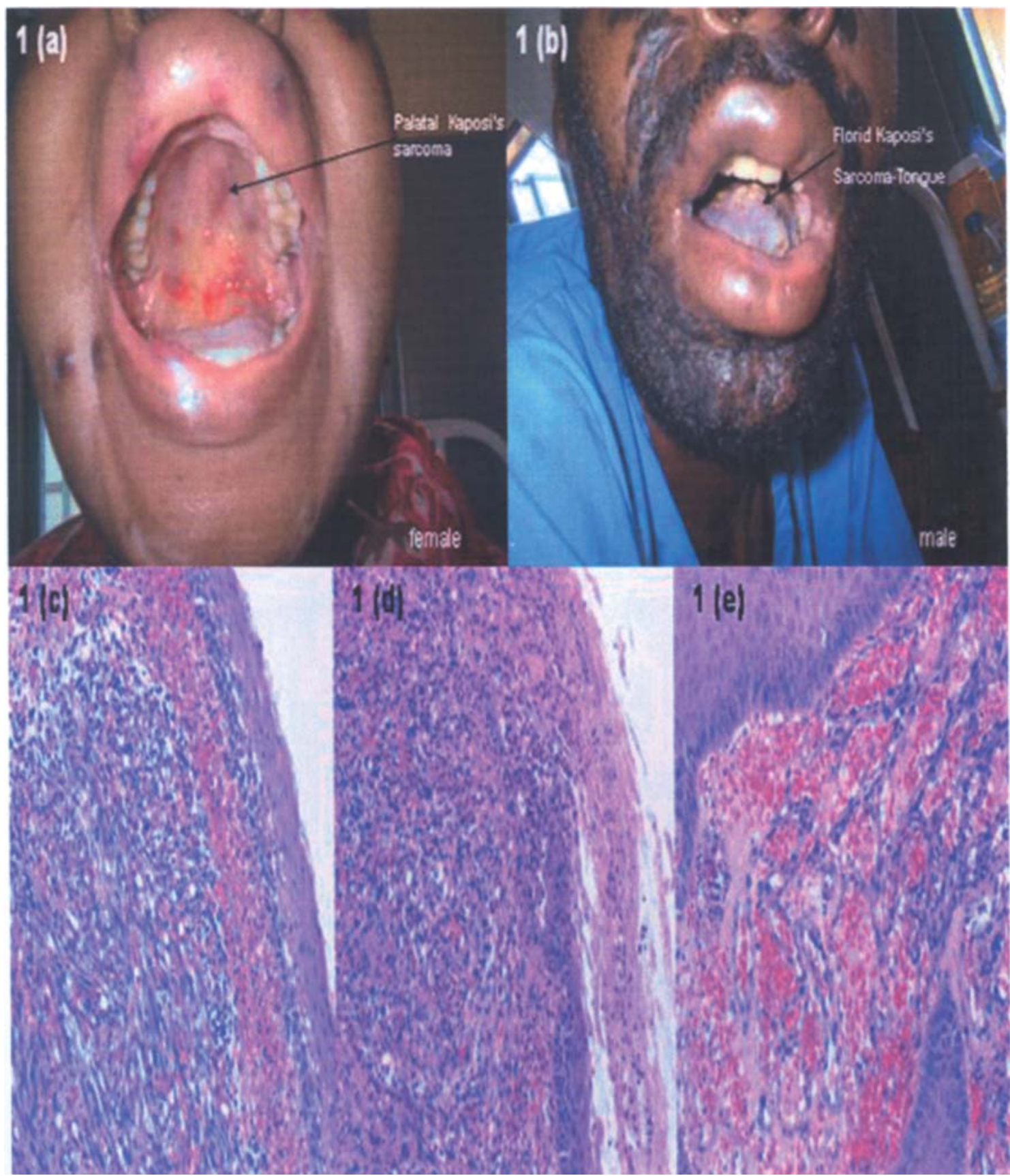

Figure 1. Oral AIDS-related Kaposi's sarcoma multicentric lesions in (a) the palate and lips of a Tanzanian female and (b) tongue of a Tanzanian male. Note the cutaneous dissemination in both patients. Haematoxylin and eosin (H\&E) sections of OAKS of nodular stage (c) and (d). Note mucosal ulceration (d), and an angiomatous KS lesion (e) (x400).

Histopathology. Out of the 78 OKS biopsies, $17(21.8 \%)$ presented with patch KS; $13(16.6 \%)$, plaque; and $48(61.5 \%)$, nodular histopathology, respectively (Table II, Fig. 1b-f) and 36/48 (75.0\%) patients with nodular-stage histology had apparently de novo non-disseminated OKS at first diagnosis (p-value $=0.0013$, ANOVA). Moreover, all children with OKS (5) presented with nodular-stage disease.

Immunohistochemistry (IHC). The ABC and IFA observations are summarized in Tables III and IV and Fig. 2a-d. All KS biopsies were positive for LANA (Fig 2a and b), CD34 (Fig. 2b and d) and Ki-67 (Fig. 2c and d) markers but nodular OAKS in adult males had more LANA+ cells (median $=67.6 \%)$ than females $(40.4 \%)$, a statistically significant difference $(\mathrm{p}$-value $=0.02)$ although the number of adult males with nodular OAKS was small (Table III). Similarly, LANA ${ }^{+}$granules/nucleus in adult nodular OAKS showed a somewhat higher median value in male $(18.5 \mathrm{gr} / \mathrm{n})$ compared to female $(10.0 \mathrm{gr} / \mathrm{n})$ biopsies although not statistically significant ( $p$-value $=0.086$ ). Concordantly, biopsies from adult male nodular oral AKS had more (median $=64.9 \%) \mathrm{LANA}^{+} / \mathrm{CD} 4^{+}[\mathrm{KS}$ spindle-cells $(\mathrm{SC})]$ per HPF compared to females $(45.9 \%)$, a statistically significant difference ( $\mathrm{p}$-value $=0.03$ ) (Table III). A gender difference was also observed with regard to tumour cell proliferation in adult OAKS with a statistically significant ( $\mathrm{p}$-value $=0.04$ ) difference 

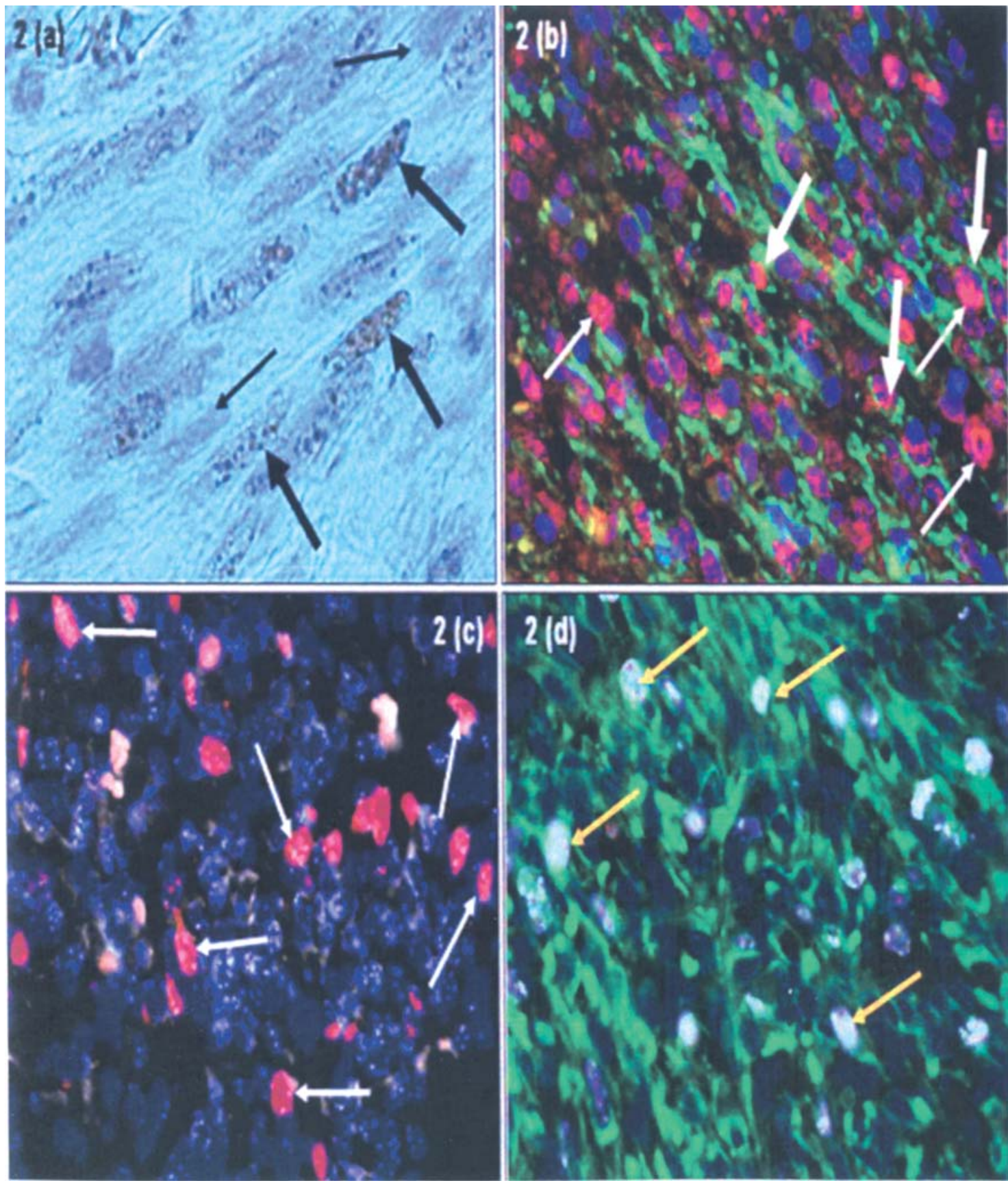

Figure 2. (a) Avidin-biotin complex (ABC) immunoperoxidase-stained paraffin section showing KS spindle cells (SC) with brown nuclear HHV-8 LANApositive granules (thick arrows) and some LANA-negative SC (thin arrows) (x1000). (b) Triple immunofluorescence (IFA)-stained paraffin section of OAKS showing (pink dots) nuclear HHV-8 LANA-positive granules, (green) diffuse CD34 (SC marker) staining and (blue) 6-diamidino-2-phenylindole (DAPI) nuclear DNA counterstaining. $\mathrm{LANA}^{+} / \mathrm{CD} 34^{+} \mathrm{SC}$ (thick arrows), the high quantity of LANA ${ }^{+}$granules/nucleus (thin arrows) and some infiltrating inflammatory cells LANA-CD34- cells (x400). (c) Immunofluorescence (IFA)-stained OAKS paraffin section showing (pink) diffuse Ki-67 nuclear reactivity reflecting tumour cell proliferation and (white dots) granular HHV-8 LANA nuclear staining. Note that most proliferating cells are LANA (white arrows). Nuclear DAPI DNA staining (blue) (x400). (d) Immunofluorescence (IFA)-stained OAKS paraffin section showing (green) diffuse CD34 staining and (white) diffuse nuclear Ki-67 antigen. Note that almost all proliferating cells (white arrows) are CD34+. Blue colour DAPI nuclear DNA staining (x400).

in mean Ki-67+ cell frequency for males $(23.5 \%)$ and females $(18.0 \%)$ (Table III). This was apparent also from evaluations of proliferating $\left(\mathrm{Ki}-67^{+}\right)$, HHV-8 infected $\left(\mathrm{LANA}^{+}\right) \mathrm{SC}$ $\left(\mathrm{CD} 34^{+}\right)$cells (triple positive cells) which were statistically significantly higher in male (median $=19.3 \%$ ) than in female nodular OAKS $($ median $=9.5 \%)(p$-value $=0.02)($ Table III) . Furthermore, the frequency of triple-positive cells was also found to be significantly higher in male (median $=17.6 \%$, mean $=20.4 \%$ ) than in female OAKS (median $=10.1 \%$, mean
$=11.2 \%)$ in unmatched biopsies (p-value $=0.03$ ) (Table IV). Moreover, an apparent correlation $\left(\mathrm{R}^{2}=0.56\right.$ or $\left.56 \%\right)$ was found between LANA and $\mathrm{Ki}-67$ immunoreactivity in adult OAKS biopsies, particularly with regard to $\mathrm{LANA}^{+} / \mathrm{CD} 4^{+}$ $\mathrm{SC}\left(\mathrm{R}^{2}=0.59\right.$ or $\left.60 \%\right)$ (Fig. 3 ).

IFA also showed cell count differences between children $<15$ and adults $\geq 15$ years respectively (Table III and IV) and that childhood compared to adult OAKS had significantly higher median $\mathrm{LANA}^{+}$, $\mathrm{LANA}^{+} / \mathrm{CD}_{3} 4^{+}$and $\mathrm{LANA}^{+} / \mathrm{CD} 34^{+} /$ 
Table III. Matched triple-IFA cell count comparison for (A) male-female nodular oral AIDS-related Kaposi's sarcoma (OAKS), (B) juvenile vs adult OAKS and (C) OAKS vs cutaneous HIV/AIDS Kaposi's sarcoma (CAKS).

\begin{tabular}{|c|c|c|c|c|c|c|c|c|c|}
\hline Cell markers & Range & Mean & Median & $\mathrm{SD}$ & Range & Mean & Median & SD & p-values \\
\hline A. (21 biopsies) & \multicolumn{4}{|c|}{ Adult male nodular OAKS (4) } & \multicolumn{4}{|c|}{ Adult female nodular OAKS (17) } & \\
\hline $\mathrm{LANA}^{+}$ & $53.4-73.3$ & 66.5 & 67.6 & 10.5 & $27.6-71.9$ & 45.1 & 40.4 & 13.6 & 0.02 \\
\hline $\mathrm{LANA}^{+} \mathrm{gr} / \mathrm{n}$ & $10.0-23.0$ & 17.5 & 18.5 & 5.6 & $5.0-22.0$ & 12.1 & 10.0 & 5.3 & 0.086 \\
\hline $\mathrm{LANA}^{+} / \mathrm{CD} 34^{+}$ & $53.5-72.2$ & 63.8 & 64.9 & 7.9 & $27.6-71.9$ & 47.1 & 45.9 & 13.1 & 0.03 \\
\hline $\mathrm{Ki}-67^{+}$ & $14.3-28.7$ & 23.5 & 24.1 & 5.8 & $11.1-30.0$ & 18.0 & 17.2 & 5.2 & 0.04 \\
\hline $\mathrm{LANA}^{+} / \mathrm{CD} 34^{+} / \mathrm{Ki}-67^{+}$ & $9.8-61.3$ & 27.4 & 19.3 & 23.0 & $5.6-18.8$ & 10.7 & 9.5 & 4.1 & 0.02 \\
\hline B. (26 biopsies) & \multicolumn{4}{|c|}{ Juvenile nodular OAKS (5) } & \multicolumn{4}{|c|}{ Adult nodular OAKS (21) } & \\
\hline $\mathrm{LANA}^{+}$ & $68.7-74.4$ & 71.8 & 72.3 & 2.9 & $27.5-77.3$ & 49.0 & 45.9 & 15.3 & 0.018 \\
\hline $\mathrm{LANA}^{+} \mathrm{gr} / \mathrm{n}$ & $15.0-30.0$ & 24.3 & 28.0 & 8.1 & $5.0-23.0$ & 12.8 & 12.8 & 5.5 & 0.03 \\
\hline $\mathrm{LANA}^{+} / \mathrm{CD} 34+$ & $68.7-74.1$ & 71.7 & 72.3 & 2.7 & $27.6-72.2$ & 50.0 & 49.0 & 13.9 & 0.008 \\
\hline $\mathrm{Ki}-67^{+}$ & $20.8-29.0$ & 24.2 & 22.8 & 4.3 & $11.1-30.0$ & 18.6 & 17.2 & 5.3 & 0.06 \\
\hline $\mathrm{LANA}^{+} / \mathrm{CD} 34^{+} / \mathrm{Ki}-67^{+}$ & $16.0-21.3$ & 18.1 & 17.0 & 2.8 & $5.3-61.3$ & 13.2 & 10.4 & 10.8 & 0.05 \\
\hline C. (41 biopsies) & \multicolumn{4}{|c|}{ Adult nodular OAKS (23) } & \multicolumn{4}{|c|}{ Adult nodular CAKS (18) } & \\
\hline LANA $^{+}$ & $27.5-77.3$ & 51.5 & 52.4 & 16.2 & $6.6-54.7$ & 42.3 & 40.8 & 8.0 & 0.03 \\
\hline $\mathrm{CD} 34^{+}$ & $73.0-98.9$ & 90.3 & 94.3 & 8.4 & 48.1 & 77.3 & 79.1 & 11.4 & 0.002 \\
\hline $\mathrm{LANA}^{+} / \mathrm{CD} 34^{+}$ & $27.6-72.2$ & 50.0 & 51.3 & 13.9 & $24.9-53.7$ & 41.0 & 41.7 & 10.1 & 0.07 \\
\hline $\mathrm{Ki}-67^{+}$ & $11.1-30.0$ & 18.6 & 17.2 & 5.3 & $0-18.7$ & 5.0 & 4.5 & 5.3 & 0.00003 \\
\hline $\mathrm{LANA}^{+} / \mathrm{CD} 34^{+} / \mathrm{Ki}-67^{+}$ & $5.6-61.3$ & 13.2 & 10.1 & 10.8 & $0-11.7$ & 3.1 & 1.5 & 4.4 & 0.0002 \\
\hline
\end{tabular}

SD, standard deviation; SC, spindle-cells; IFA, immunofluorescence; $\mathrm{L}^{+} \mathrm{C}^{+}, \mathrm{HHV}-8^{+} / \mathrm{CD} 34^{+} ; \mathrm{L}^{+} \mathrm{C}^{+} \mathrm{K}^{+}, \mathrm{LANA}^{+} / \mathrm{CD} 34^{+} / \mathrm{Ki}-67^{+}$cells; gr/n, granules/ nucleus.

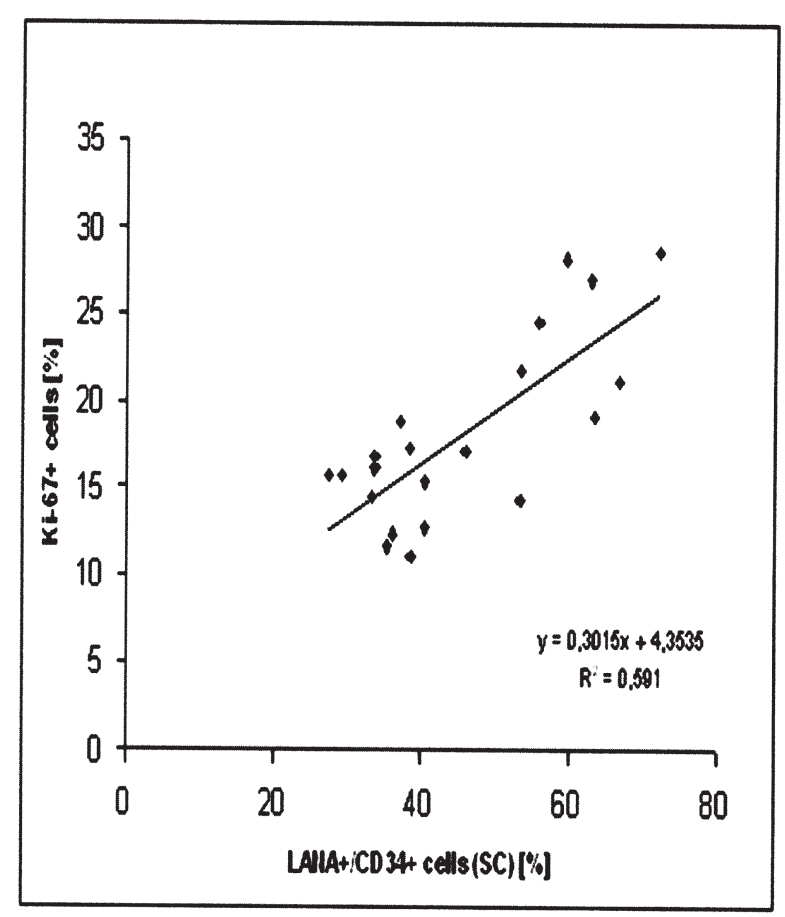

Figure 3. Scatter diagram showing approximately $60 \%$ positive correlation $\left(\mathrm{R}^{2}=0.59\right)$, between Ki-67 proliferation index and human herpesvirus- 8 (HHV-8)-infected Kaposi's sarcoma (KS) spindle cells (SC) $\left(\mathrm{LANA}^{+} / \mathrm{CD} 34^{+}\right.$ cells) in the oral KS lesions as shown by triple-immunofluorescence studies.
$\mathrm{Ki}-67^{+}$cell counts and also higher median $\mathrm{LANA}^{+}$granule counts (Table III and IV). Moreover, the median $\mathrm{Ki}-67^{+}$count also appeared higher in children $(22.8 \%)$ than adult $(17.2 \%)$ nodular OAKS with an almost statistically significant difference (p-value $=0.06$ ) (Table III). No children with cutaneous AKS (CAKS) biopsies were available for comparison.

Comparison of nodular OAKS and CAKS showed that $\mathrm{LANA}^{+}$cells were significantly ( $\mathrm{p}$-value $=0.03$ ) more frequent both in matched (Table III) and unmatched biopsies (Table IV). Also, $\mathrm{LANA}^{+} / \mathrm{CD}_{34}+\mathrm{SC}$ appeared to be more frequent in nodular OAKS than CAKS although the difference was not statistically significant (Tables III and IV). CD34+ $4^{+} \mathrm{Ki}-67^{+}$as well as triple-positive $\left(\mathrm{LANA}^{+} / \mathrm{CD} 34^{+} / \mathrm{Ki}-67^{+}\right)$cells, were more frequent in nodular OAKS than in CAKS (Tables III and IV), with high statistical significance ( $\mathrm{p}$-value $=0.002$, 0.00003 and 0.0002 respectively).

\section{Discussion}

Oral KS (OKS) particularly in HIV patients (OAKS) has been reported in Africa, Europe and America but less in Asian populations $(13,14,25,26)$ and the present cohort of 78 OKS corresponds to approximately $11 \%$ of all (700) KS cases collected at MUCHS/MNH from 1990-2005. These OKS showed a high $(84.6 \%)$ HIV association consistent with the notion that OKS is an important clinical indicator for AIDS 
Table IV. Unmatched triple-IFA cell count comparison for (A) male vs female oral AIDS-related Kaposi's sarcoma (OAKS), (B) juvenile vs adult OAKS and (C) OAKS vs cutaneous HIV/AIDS Kaposi's sarcoma (CAKS).

\begin{tabular}{|c|c|c|c|c|c|c|c|c|c|}
\hline Cell markers & Range & Mean & Median & SD & Range & Mean & Median & $\mathrm{SD}$ & p-values \\
\hline A. (29 biopsies) & \multicolumn{4}{|c|}{ Male OAKS (8) } & \multicolumn{4}{|c|}{ Female OAKS (21) } & \\
\hline LANA $^{+}$ & $14.0-77.3$ & 56.0 & 65.8 & 24.0 & $27.6-72.3$ & 45.6 & 40.6 & 14.2 & 0.17 \\
\hline $\mathrm{LANA}^{+} \mathrm{gr} / \mathrm{n}$ & $5.0-28.0$ & 16.3 & 16.0 & 7.4 & $5.0-30.0$ & 13.1 & 12.0 & 6.4 & 0.2 \\
\hline $\mathrm{LANA}^{+} / \mathrm{CD} 34^{+}$ & $14.0-74.1$ & 55.0 & 64.9 & 22.8 & $27.6-72.3$ & 48.9 & 46.7 & 13.9 & 0.2 \\
\hline $\mathrm{Ki}-67^{+}$ & $14.3-29.1$ & 21.9 & 21.0 & 5.7 & $11.1-30.0$ & 18.2 & 17.2 & 5.2 & 0.09 \\
\hline $\mathrm{LANA}^{+} / \mathrm{CD} 34^{+} / \mathrm{Ki}-67^{+}$ & $5.3-61.3$ & 20.4 & 17.6 & 17.4 & $5.6-18.8$ & 11.2 & 10.1 & 4.2 & 0.03 \\
\hline
\end{tabular}

B. (29 biopsies)

\begin{tabular}{|c|c|c|c|c|c|c|c|c|c|}
\hline B. (29 biopsies) & & Juver & $\mathrm{KS}(5)$ & & & Adult & (24) & & \\
\hline $\mathrm{LANA}^{+}$ & $68.7-74.4$ & 71.8 & 72.3 & 2.9 & $14.0-77.3$ & 46.6 & 43.3 & 16.5 & 0.015 \\
\hline $\mathrm{LANA}^{+} \mathrm{gr} / \mathrm{n}$ & $15.0-30.0$ & 24.3 & 28.0 & 8.1 & $5.0-23.0$ & 12.8 & 12.8 & 5.5 & 0.003 \\
\hline $\mathrm{LANA}^{+} / \mathrm{CD} 34+$ & $68.7-74.1$ & 71.7 & 72.3 & 2.7 & $27.6-72.2$ & 50.0 & 49.0 & 13.9 & 0.008 \\
\hline $\mathrm{Ki}-67^{+}$ & $20.8-29.0$ & 24.2 & 22.8 & 4.3 & $11.1-30.0$ & 18.6 & 17.2 & 5.3 & 0.06 \\
\hline $\mathrm{LANA}^{+} / \mathrm{CD} 34^{+} / \mathrm{Ki}-67^{+}$ & $16.0-21.3$ & 18.1 & 17.0 & 2.8 & $5.3-61.3$ & 13.2 & 10.4 & 10.8 & 0.05 \\
\hline
\end{tabular}

C. (50 biopsies)

LANA $^{+}$

$\mathrm{CD} 34^{+}$

$\mathrm{LANA}^{+} / \mathrm{CD} 34^{+}$

$\mathrm{Ki}-67^{+}$

$\mathrm{LANA}^{+} / \mathrm{CD} 34^{+} / \mathrm{Ki}-67^{+}$
OAKS (29)

\begin{tabular}{rrrr}
\hline $27.5-77.3$ & 49.0 & 48.2 & 17.5 \\
$49.6-98.9$ & 88.6 & 94.6 & 11.5 \\
$14.0-74.1$ & 50.5 & 51.6 & 16.6 \\
$11.1-30.0$ & 19.2 & 18.5 & 5.4 \\
$5.3-61.3$ & 13.7 & 10.7 & 10.3
\end{tabular}

\begin{tabular}{|c|c|c|c|c|}
\hline \multicolumn{4}{|c|}{ CAKS (21) } & \multirow[b]{2}{*}{0.03} \\
\hline $6.6-54.7$ & 39.3 & 40.6 & 12.5 & \\
\hline $15.6-90.5$ & 70.1 & 75.7 & 18.7 & 0.0005 \\
\hline $24.9-53.7$ & 41.0 & 41.7 & 10.1 & 0.09 \\
\hline $0-18.7$ & 6.9 & 5.8 & 5.7 & $<0.0000$ \\
\hline $0-11.7$ & 3.3 & 1.6 & 3.7 & $<0.0000$ \\
\hline
\end{tabular}

SD, standard deviation; SC, spindle-cells; IFA, immunofluorescence; $\mathrm{L}^{+} \mathrm{C}^{+}, \mathrm{HHV}-8^{+} / \mathrm{CD} 34^{+} ; \mathrm{L}^{+} \mathrm{C}^{+} \mathrm{K}^{+}, \mathrm{LANA}^{+} / \mathrm{CD} 34^{+} / \mathrm{Ki}-67^{+}$cells; gr $/ \mathrm{n}$, granules/ nucleus.

$(12,27,28)$. In Canada, OKS was reported to constitute approximately $2 \%$ of KS cases where it was identified as the first malignant diagnosis in AIDS patients (29). A South African (SA) study reported a total of 81 OKS cases collected during 1973-2002 of which 68 (84\%) cases occurred after 1997 reflecting a marked increased frequency of the HIV epidemic (6). However, these hospital-based figures are prone to selection bias and not very representative for the general populations, thus limiting comparability. Nevertheless, our findings suggest a comparatively high frequency of OKS in Tanzania.

The apparent predominance of females [male:female ratio $=1: 2.3$ ] in this Tanzanian OKS cohort, is obviously in contrast with the usual male $\mathrm{KS}$ predominance reported previously $(4,6,12-14)$. Although the reasons for this female OKS predominance are not clear and may include a recruitment bias, it is noteworthy that other reports from East Africa have recorded a dramatic male:female ratio decline (11-fold) in KS from 19:1 (1960-71) to 1.7:1 (1991-97) $(15,16,30)$. This is also supported by findings of an even lower male:female ratio of 1.3:1 amongst patients with OKS in SA (6). In Zimbabwe however, a male:female ratio of 3:1 for OAKS and 4:1 for other oral HIV manifestations were recently recorded and more similar to Western reports where gender distribution is influenced by a relatively high frequency of $\mathrm{KS}$ among homosexuals $(13,14)$. The gender differences in KS are of interest considering previous suggestions of lower female risk, possibly attributed to hormonal factors including human chorionic gonadotropin (hCG)-in pregnant women $(1,31,32)$, although some reports disagree $(30,33)$. Considering the well documented male:female ratio decline for AKS in Africa (including Tanzania) $(15,16,30)$ it seems likely that this reflects ongoing changes in heterosexual behaviour since KSHV is known to be sexually transmissible $(9,10)$. However, the peak age (25-35) of OAKS and the high frequency of patients aged 15-49 years in our study, is representative of the sexually active population and evidently suggests the association of sexual behaviour with OAKS development. Obviously, the age distribution of oral AKS in Tanzania also reflects that of the group most affected by the HIV epidemic. However, geographical $(6,13,26,29)$, age $(17,34)$ and genderrelated $(13,14)$ variations may also be related to host (HLA, immunity) $(17,35)$, environmental (35) factors and/or virological (HHV-8 and HIV subtypes) (36) and also to yet unknown differences in pathogenetic/biologic mechanisms.

The factors related to the apparently increased susceptibility of the palate over other buccal tissues to generate KS lesions are not known and may be rather complex $(6,27)$. The fact that most OAKS in our cohort were localized lesions and mostly late-nodular stage suggests that OAKS may be a distinct clinical entity $(6,27)$. 
The apparently higher lesional HHV-8 content and tumour proliferation index $(\mathrm{PI})\left(\mathrm{Ki}-67^{+}\right.$cell frequency) in male than female lesions, as well as the predilection to systemic dissemination and multicentricity of oral lesions in males compared to females, agrees with the notion that $\mathrm{KS}$ is predominantly a male disease. Thus at the tissue level, males may be more susceptible to HHV-8 infection than females $(4,12-14)$. Similarly, OAKS in children also had significantly more HHV-8 tumour cell association than adults which is in agreement with other African HHV-8 seroprevalence reports $(34,37)$ and may indicate, for unclear reasons, increased susceptibility in children $(17,34)$ and also emphasizes the importance of horizontal transmission (oral exposure) in families possibly initiated by vertical mother-to-child transmission $(9,34,37,38)$. However, the small numbers of both male and children biopsies available in our cohort limit definitive conclusions. The apparent higher HHV-8 content and cell proliferation index (PI) in oral than cutaneous AKS (CAKS) also indicates that the oral cavity is an important portal of entry and reservoir for HHV-8. In contrast, the skin, although most often the primary site of KS, appears a less important route of transmission $(9,18,19)$. Our findings of a significantly higher PI in oral than cutaneous KS are supported by other observations based on skin KS $(4,39)$ and the observed $(60 \%)$ correlation between tumour PI and $\mathrm{LANA}^{+} / \mathrm{CD} 4^{+} \mathrm{SC}$ appears to indicate that tumour cell (SC) proliferation is partly viral (HHV-8)-induced and that virus accumulation therefore is due to the proliferation of HHV-8infected SC. However, tumour growth appears also dependent on the recruitment of uninfected progenitor cells $(4,40)$. In previous studies, we have shown that total cell PI was higher in early than late CAKS lesions and not significantly different between nodular AKS and EKS (4) but comparison of oral vs cutaneous and juvenile vs adult KS as in the present study, was not previously reported $(4,39)$. The findings of higher PI in male vs female, children vs adults and oral vs cutaneous KS correspond with HHV-8 LANA results and appear indicative of a less favourable pathogenesis for OKS in general, and in males and children in particular which entertains the notion of greater disease burden in males $(4,6,20)$. The observed differences in PI were clearly correlated with tissue KSHV/HHV-8 content. Furthermore, the fact that gender differences were most evident in the matched (nodular KS) group seems to indicate that they are dependent on tumour stage. Thus, the differences in gender, age-group and tissue affected found in the present study reflect the complex pathogenesis of KS development.

In conclusion, our study shows a) that oral Kaposi's sarcoma $(\mathrm{OKS})$ is frequent $(11 \%)$ among $\mathrm{KS}$ patients at the Muhimbili-National Hospital/-University College, Dar es Salaam, Tanzania; b) that OKS is highly associated with HIV infection and advanced (nodular) histological stage; c) that the HHV-8 lesional content (LANA immunoreactivity) is higher in nodular oral AIDS-related KS (AKS) lesions of males than females and of children than adults; d) that males appeared to have more tumour burden (multicentricity and systemization) although OKS frequency among females is seemingly higher; and (e) oral AKS had higher HHV-8 content than cutaneous AKS which appeared correlated to tumoral proliferation index.

\section{Acknowledgements}

The technical assistance of Onjection Byobangamba, Angelika Magogo and Vera Nelson (MUCHS/MNH) and Marianne Ekman (Karolinska Institute) is gratefully appreciated. The Ocean Road Cancer Institute (ORCI), the Dental and General/Paediatric Surgery departments (MUCHS/MNH) and peripheral hospitals kindly provided the biopsies. Jafari Sufi [Microbiology/Immunology department (MUCHS)], Malin Enbom and Professor Annika Linde's group (SMIKarolinska Institute) are gratefully acknowledged for HHV-8 serology. These studies were approved by the MUCHS Research Ethics Committee and the Karolinska Institute (KI). Financial support was provided by the Swedish International Development Agency (SIDA), Department of Research Cooperation (SAREC), Cancer Fonden, KI Fonden.

\section{References}

1. Bisacchi D, Noonan DM, Carlone S, Albini A and Pfeffer U: Kaposi's sarcoma and human chorionic gonadotropin: mechanisms, moieties and mysteries. Biol Chem 383: 1315-1320, 2002.

2. Chang Y, Cesarman E, Pessin MS, Lee F, Culpepper J, Knowles DM and Moore PS: Identification of herpesvirus-like DNA sequences in AIDS-associated Kaposi's sarcoma. Science 266: 1865-1869, 1994.

3. Bakari M, Pallangyo K, Kitinya J, Mbena E and Urassa W: The importance of clinical features in differentiating HIV related from non-HIV related Kaposi's sarcoma: experience from Dar es Salaam, Tanzania. Trop Doct 26: 104-107, 1996.

4. Pyakurel P, Massambu C, Castanos-Velez E, Ericsson S, Kaaya E, Biberfeld $\mathrm{P}$ and Heiden T: Human herpesvirus $8 / \mathrm{Kaposi}$ sarcoma herpesvirus cell association during evolution of Kaposi sarcoma. J Acquir Immune Defic Syndr 36: 678-683, 2004.

5. Cannon MJ, Dollard SC, Black JB, Edlin BR, Hannah C, Hogan SE, Patel MM, Jaffe HW, Offermann MK, Spira TJ, Pellett PE and Gunthel CJ: Risk factors for Kaposi's sarcoma in men seropositive for both human herpesvirus 8 and human immunodeficiency virus. Aids 17: 215-222, 2003.

6. Lager I, Altini M, Coleman H and Ali H: Oral Kaposi's sarcoma: a clinicopathologic study from South Africa. Oral Surg Oral Med Oral Pathol Oral Radiol Endod 96: 701-710, 2003.

7. Hammock L, Reisenauer A, Wang W, Cohen C, Birdsong G and Folpe AL: Latency-associated nuclear antigen expression and human herpesvirus- 8 polymerase chain reaction in the evaluation of Kaposi sarcoma and other vascular tumors in HIV-positive patients. Mod Pathol 18: 463-468, 2005.

8. Patel RM, Goldblum JR and Hsi ED: Immunohistochemical detection of human herpes virus- 8 latent nuclear antigen- 1 is useful in the diagnosis of Kaposi sarcoma. Mod Pathol 17: 456-460, 2004.

9. Hille JJ, Webster-Cyriaque J, Palefski JM and Raab-Traub N: Mechanisms of expression of HHV8, EBV and HPV in selected HIV-associated oral lesions. Oral Dis 8 (suppl 2): 161-168, 2002.

10. Webster-Cyriaque J, Duus K, Cooper C and Duncan M: Oral EBV and KSHV infection in HIV. Adv Dent Res 19: 91-95, 2006.

11. Pak F, Pyakural P, Kokhaei P, Kaaya E, Pourfathollah AA, Selivanova $\mathrm{G}$ and Biberfeld P: $\mathrm{HHV}-8 / \mathrm{KSHV}$ during the development of Kaposi's sarcoma: evaluation by polymerase chain reaction and immunohistochemistry. J Cutan Pathol 32: 21-27, 2005

12. Enbom M, Urassa W, Massambu C, Thorstensson R, Mhalu F and Linde A: Detection of human herpesvirus 8 DNA in serum from blood donors with HHV-8 antibodies indicates possible bloodborne virus transmission. J Med Virol 68: 264-267, 2002.

13. Patton LL, Phelan JA, Ramos-Gomez FJ, Nittayananta W, Shiboski CH and Mbuguye TL: Prevalence and classification of HIV-associated oral lesions. Oral Dis 8 (suppl 2): 98-109, 2002.

14. Shiboski CH: Epidemiology of HIV-related oral manifestations in women: a review. Oral Dis 3 (suppl 1): S18-S27, 1997.

15. Onyango JF and Njiru A: Kaposi's sarcoma in a Nairobi hospital. East Afr Med J 81: 120-123, 2004. 
16. Thomas JO: Acquired immunodeficiency syndrome-associated cancers in Sub-Saharan Africa. Semin Oncol 28: 198-206, 2001.

17. Amir H, Kaaya EE, Manji KP, Kwesigabo G and Biberfeld P Kaposi's sarcoma before and during a human immunodeficiency virus epidemic in Tanzanian children. Pediatr Infect Dis J 20 : 518-521, 2001

18. Zago A, Bourboulia D, Viana MC, Collandre H, Dietze R, Boshoff C and Keller R: Seroprevalence of human herpesvirus 8 and its association with Kaposi sarcoma in Brazil. Sex Transm Dis 27: 468-472, 2000 .

19. Pauk J, Huang ML, Brodie SJ, Wald A, Koelle DM, Schacker T, Celum C, Selke S and Corey L: Mucosal shedding of human herpesvirus 8 in men. N Engl J Med 343: 1369-1377, 2000.

20. Casper C, Redman M, Huang ML, Pauk J, Lampinen TM, Hawes SE, Critchlow CW, Morrow RA, Corey L, Kiviat N and Wald A: HIV infection and human herpesvirus- 8 oral shedding among men who have sex with men. J Acquir Immune Defic Syndr 35: 233-238, 2004.

21. Drury RAB and Wallinton EA: Carleton's Histological Technique. 5th edition. Oxford University Press, New York/Toronto, 1980.

22. Urassa W, Bakari M, Sandstrom E, Swai A, Pallangyo K, Mbena E, Mhalu F and Biberfeld G: Rate of decline of absolute number and percentage of CD4 $\mathrm{T}$ lymphocytes among HIV-1infected adults in Dar es Salaam, Tanzania. Aids 18: 433-438, 2004.

23. Urassa WK, Kaaya EE, Kitinya JN, Lema LEK, Amir H, Luande J, Biberfeld G, Mhalu FS and Biberfeld P: Immunological profile of endemic and epidemic Kaposi's sarcoma patients in Dar-esSalaam, Tanzania. Int J Mol Med 1: 979-982, 1998.

24. Urassa WK, Mbena EM, Swai AB, Gaines H, Mhalu FS and Biberfeld G: Lymphocyte subset enumeration in HIV seronegative and HIV-1 seropositive adults in Dar es Salaam, Tanzania: determination of reference values in males and females and comparison of two flow cytometric methods. J Immunol Methods 277: 65-74, 2003.

25. Lim AA, Leo YS, Lee CC and Robinson AN: Oral manifestations of human immunodeficiency virus (HIV)-infected patients in Singapore. Ann Acad Med Singapore 30: 600-606, 2001.

26. Jonsson N, Zimmerman M, Chidzonga MM and Jonsson K: Oral manifestations in 100 Zimbabwean HIV/AIDS patients referred to a specialist centre. Cent Afr J Med 44: 31-34, 1998

27. Greenspan JS and Greenspan D: The epidemiology of the oral lesions of HIV infection in the developed world. Oral Dis 8 (suppl 2): 34-39, 2002.

28. Massambu C, Pyakurel P, Kaaya E, Enbom M, Urassa W, Demirhan I, Loewer J, Linde A, Chandra A, Heiden T, Doerr HW, Chandra P, et al: Serum HHV8 DNA and Tat antibodies in Kaposi's sarcoma patients with and without HIV-1 infection. Anticancer Res 23: 2389-2395, 2003
29. Gorsky M and Epstein JB: A case series of acquired immunodeficiency syndrome patients with initial neoplastic diagnoses of intraoral Kaposi's sarcoma. Oral Surg Oral Med Oral Pathol Oral Radiol Endod 90: 612-617, 2000

30. Pantanowitz L and Dezube BJ: Kaposi's sarcoma and pregnancy. Am J Perinatol 22: 457, 2005.

31. Hermans P: Epidemiology, etiology and pathogenesis, clinical presentations and therapeutic approaches in Kaposi's sarcoma: 15-year lessons from AIDS. Biomed Pharmacother 52: 440-446, 1998.

32. Samaniego F, Bryant JL, Liu N, Karp JE, Sabichi AL, Thierry A, Lunardi-Iskandar Y and Gallo RC: Induction of programmed cell death in Kaposi's sarcoma cells by preparations of human chorionic gonadotropin. J Natl Cancer Inst 91: 135-143, 1999.

33. Rabkin CS, Chibwe G, Muyunda K and Musaba E: Kaposi's sarcoma in pregnant women. Nature 377: 21, 1995.

34. Sarmati L: HHV-8 infection in African children. Herpes 11: 50-53, 2004.

35. Simonart T: Role of environmental factors in the pathogenesis of classic and African-endemic Kaposi's sarcoma. Cancer Lett (In press).

36. Kajumbula H, Wallace RG, Zong JC, Hokello J, Sussman N, Simms S, Rockwell RF, Pozos R, Hayward GS and Boto W: Ugandan Kaposi's sarcoma-associated herpesvirus phylogeny: evidence for cross-ethnic transmission of viral subtypes. Intervirology 49: 133-143, 2006.

37. Mbulaiteye SM, Pfeiffer RM, Whitby D, Brubaker GR, Shao J and Biggar RJ: Human herpesvirus 8 infection within families in rural Tanzania. J Infect Dis 187: 1780-1785, 2003

38. Mbulaiteye S, Marshall V, Bagni RK, Wang CD, Mbisa G, Bakaki PM, Owor AM, Ndugwa CM, Engels EA, Katongole-Mbidde E, Biggar RJ and Whitby D: Molecular evidence for mother-to-child transmission of Kaposi sarcomaassociated herpesvirus in Uganda and K1 gene evolution within the host. J Infect Dis 193: 1250-1257, 2006.

39. De Thier F, Simonart T, Hermans P, Andre J, Van Vooren JP and Noel JC: Early- and late-stage Kaposi's sarcoma lesions exhibit similar proliferation fraction. Am J Dermatopathol 21: 25-27, 1999

40. Pyakurel P, Pak F, Mwakigonja AR, Kaaya E, Heiden T and Biberfeld P: Lymphatic and vascular origin of Kaposi's sarcoma spindle cells during tumor development. Int J Cancer 119: 1262-1267, 2006. 